\title{
Power Generation using Magnetic Levitation Vertical Axis Wind Turbine
}

\author{
Manoj L, Nithesh J, Manjunath T, Gowreesh S S
}

\begin{abstract}
The main aim of the paper is to design a windmill that operates without generator and ball bearings and to get maximum power output. The use of wind energy for energy generation is one of the oldest methods for harnessing renewable energy. Use of renewable energy is an essential ingredient of socio-economic development and economic growth. A vertical axis wind turbine (VAWT) is introduced by magnetic levitation technology to optimize the performance. The system utilizes the nature of permanent magnet as a replacement for ball bearings to levitate the turbine component and thus minimize energy losses while rotating, which is the major problem that furthermore, the system can be suited by conventional wind turbine. The Maglev Wind Turbine is expected to bring wind power technology to the next level. Furthermore, the system can be suited in use for more rural and urban areas of low speed regions. The selection of magnet materials in the design of wind turbine system will be discussed. Power will then be generated with an axial flux generator, which incorporates the use of permanent magnets and a set of coils.
\end{abstract}

Key words: VAWT, Magnetic Levitation, Wind Turbine, Blade hub, Magnet.

\section{INTRODUCTION}

The maglev power generation introduces structure and principle of the proposed magnetic levitation wind turbine for better utilisation of wind energy. Maglev wind turbine has the features of no mechanical contact, no friction etc., minimizing the damping in the magnetic levitation wind turbine, which enables the wind turbine to start up with low speed wind and work with breeze. Magnetic levitation (Maglev) is integrated into the turbine system in order to increase the efficiency. If the efficiency of the wind turbine is increased, then more power is generated thus decreasing the need for expensive power generators that cause pollution.

\section{A. Wind Energy:}

Wind is known to be another form of solar energy because it comes about as a result of uneven heating of the atmosphere by the sun coupled with the abstract topography of the earth's surface. With wind turbines, two categories of winds are relevant to their applications, namely local winds and planetary winds. The latter is the most dominant and it is usually a major factor in deciding sites for very effective wind turbines.

Revised Manuscript Received on December 30, 2019.

* Correspondence Author

Manoj L, Final Year Mechanical Engineering Students, Mechanical Engineering, JSSATE Bangalore, Karnataka, India.

Nithesh J, Final Year Mechanical Engineering Students, Mechanical Engineering, JSSATE Bangalore, Karnataka, India.

Manjunath T, Final Year Mechanical Engineering Students, Mechanical Engineering, JSSATE Bangalore, Karnataka, India.

Gowreesh S S, Associate Professor, Department of Mechanical Engineering, JSSATE Bangalore, Karnataka, India.

(C) The Authors. Published by Blue Eyes Intelligence Engineering and Sciences Publication (BEIESP). This is an open access article under the CC BY-NC-ND license (http://creativecommons.org/licenses/by-nc-nd/4.0/)
There are some reasons to support in using the wind energy to produce electricity power. Wind power available in the atmosphere is much greater than the current world energy consumption. The exploitation of wind power is only limited by the economic and environmental factors, since the resource available is far larger than any practical means to develop it. Renewable energy produced from the wind has attracted a lot of attention and support in recent years. However, this green energy is often criticized for its low output and lack of reliability.

\section{B. Wind Turbine:}

The basic working principle of a wind turbine is: When air moves quickly, in the form of wind, and their kinetic energy is captured by the turbine blades. The blades start to rotate and spin a shaft that leads from the hub of the rotor to a generator and produce electricity. In general, they are two types of wind turbine according to the axis they are rotating about. Horizontal axis wind turbine is the type of wind turbine which has a main rotor shaft and a electric generator at the top of tower and pointed to the direction of wind. Most of them possess a gear box which turns the slow rotation of turbine blades into faster rotation that is more suitable to drive an electrical generator. The main rotor shaft is arranged vertically to allow the turbine blades rotate without facing to the direction of the wind. In this system, the generator and gearbox is placed in the ground rather than on the top. There is no need of the support from a tower make it more accessible for maintenance.

\section{Magnetic Levitation:}

Magnetic levitation is a method in which an object is suspended with no support other than magnetic fields. The magnetic force produced is used to counteract the effects of gravitational force and lift up the object. By placing these two magnets on top of each other with like polarities facing each other, the magnetic repulsion will be strong enough to keep both the magnets at a distance away from each other. There are many advantages for utilizing magnetic levitation that is to minimise friction, make force measurement, design, and entertaining devices. Recently, this advance technology is applied into transportation system in which non-conducting vehicle travel safely at very high speed while suspended, guided, and propelled above a guide way by magnetic fields. The concept of magnetically levitated vehicle stimulated the development of useful application in various fields such as power generation.

\section{Maglev Wind Turbine:}

The vertically oriented blades of the wind turbine are suspended in the air above the base of the machine by using permanent magnet which produces magnetic force to lift up the blades. 


\section{Aerodynamic Analysis of Dimple effect on Airfoil}

This system does not require the electricity to operate because no electromagnets are involved. Since the turbine blades are suspended by magnetic force produce by the permanent magnet, there is no need of ball bearing to retain the blades. This allows the friction between the blades and the ball bearing can be reduced significantly and thus, minimizes the energy loss. This also helps reduce maintenance costs and increases the life span of the generator.

\section{METHODOLOGY}

> Selecting a suitable magnet for strong repulsive forceand suitable materials for rotor blades.

$>$ Appropriate materials are selected for components and are used at right areas.

$>$ Getting the prototype done and testing it.

$>$ Fabrication of the maglev wind turbine.

$>$ Testing of the working model of maglev wind turbine

$>$ If any errors are found or result is not satisfactory then examining the model and suggest the suitable changes in design or wherever it is necessary.

$>$ Getting the final model after the corrections

$>$ Installation of model at the right place.

\section{WORKING PRINCIPLE}

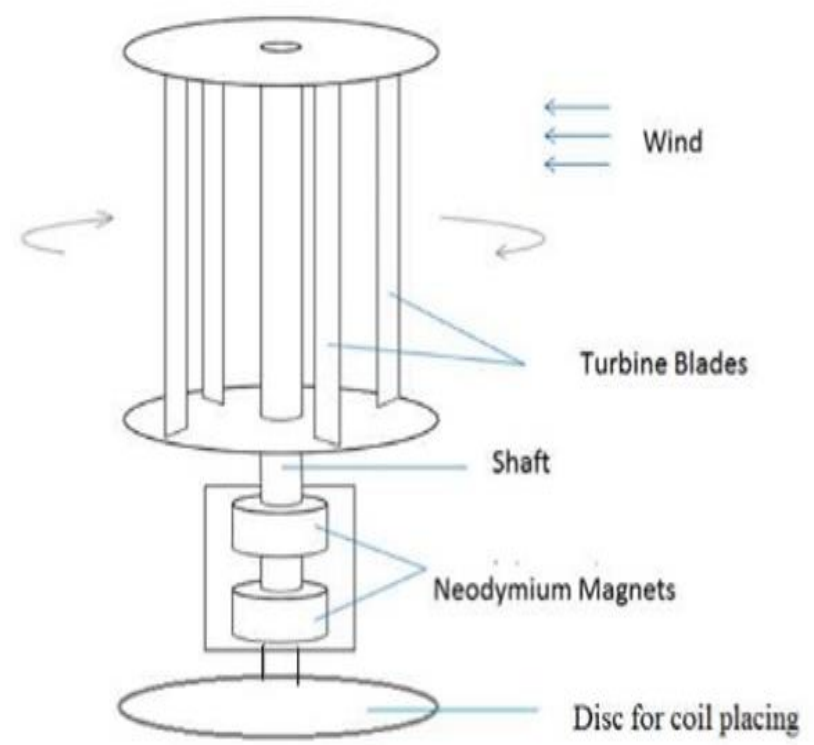

Fig.1. Sketch and components of maglev wind turbine

This is the general schematic diagram of magnetic levitation vertical axis wind turbine by which the power is generated by using Faraday's $1^{\text {st }}$ law of induction which states that "Wherever a conductor are placed in a varying magnetic field, emf are induced which is called induced emf, if the conductor circuit are closed, current are also induced which is called induced current." The wind energy rotates the wind turbine blades which are fixed to disc and to which magnets are fixed and magnetic flux of these magnets links with the coil which is placed on the base of the maglev wind mill. The following block diagram shows how the current is generated.

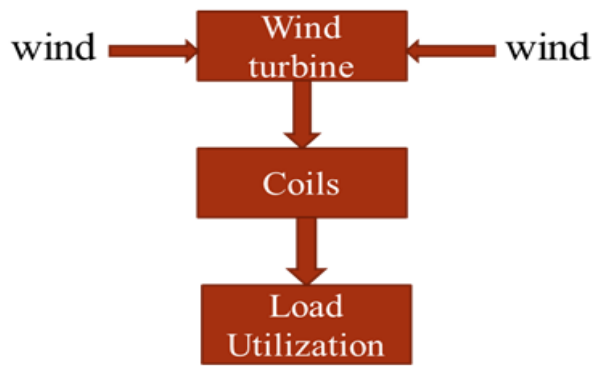

Fig.2. Block diagram of maglev wind turbine

\section{IV.DESIGN AND FABRICATION}

For CAD drawing we used the software Solid Edge, each and every component was individually drawn on the part drawing and then it was assembled in the assembly sheet.
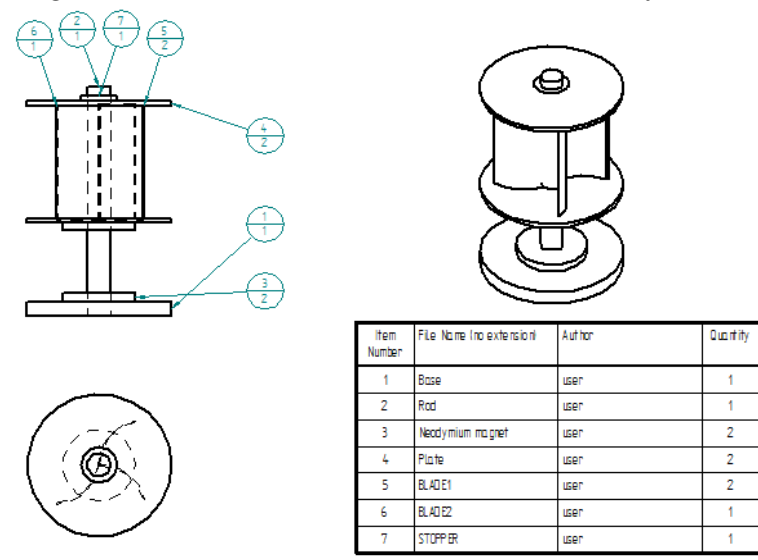

Fig. 3. Parts label of maglev wind turbine, 2D drawing

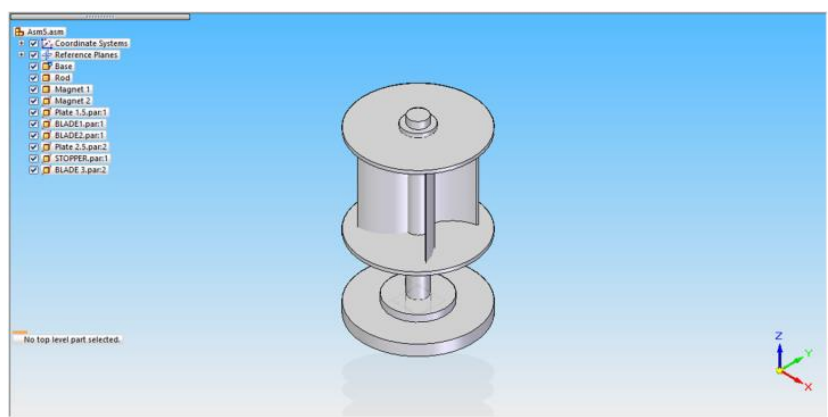

Fig.4. Isometric view of maglev wind turbine, 3D drawing

Parts used in Maglev Turbine

\section{Fixed Pole}

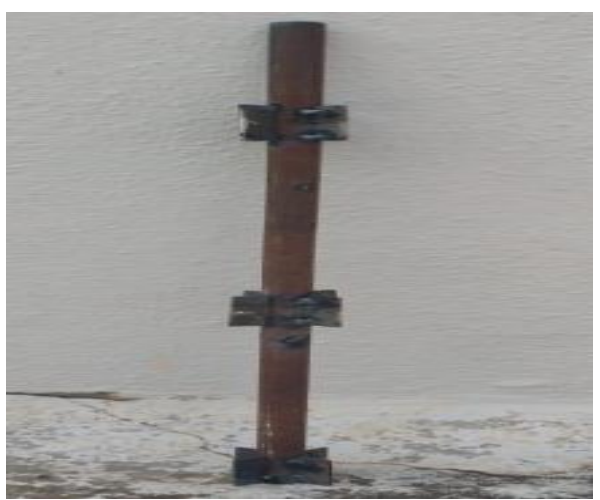

Fig.5. Fixed pole 
This part is made up of mild steel and it is cylindrical rod like structure. This is mounted on the base perpendicularly, and to which rotor plates and blades are attached to it. NdFe-B magnets are suspended on this pole which gives magnetic cushioning to the rotor component

\section{Dimensions: Diameter - 12mm Height - 800 mm}

\section{Neodymium Magnets}

It is a permanent magnet. It is also called Nd-Fe-B magnets. Two types of magnets are necessary, one is circular in shape and another is ring in shape. Ring shape magnets are used in suspension and circular shape magnets are used for power generation. Ring shape magnets have $25 \mathrm{~mm}$ outer diameter and $12 \mathrm{~mm}$ inner diameter and $6 \mathrm{~mm}$ thickness.

Circular shape magnets have $18 \mathrm{~mm}$ diameter and $2 \mathrm{~mm}$ thickness.
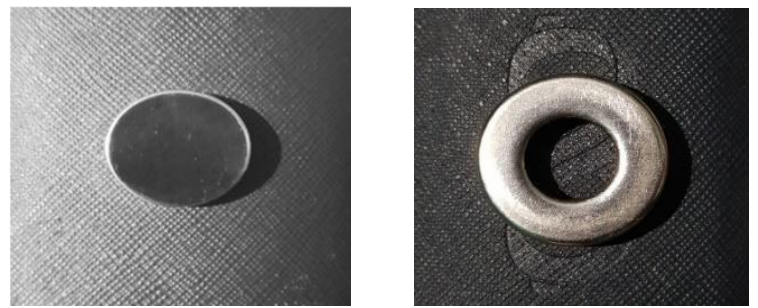

Fig. 6 Ring shape and Circular shape neodymium magnet

\section{Rotor Plates}

This is made up of acrylic sheet.It is also circular in shape and it is placed above the suspension magnet and blades areclamped to it.Acrylic sheet is used here because of its transparency nature; therefore magnets can be seen clearly as the magnets are attached at the base of the rotor plates both for the cushioning and power generation purpose.

Dimensions: Diameter - 350mm, Thickness - 6 mm

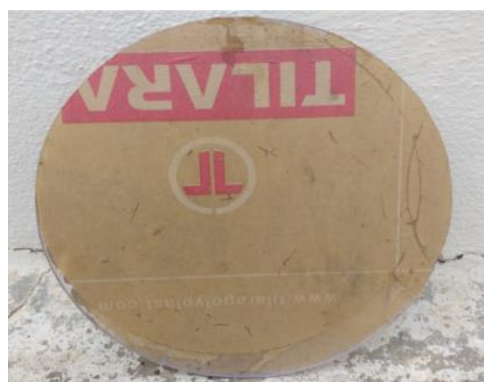

Fig. 7 Acrylic Circular Sheet

\section{Rotor Blades}

This is made up of mild steel pressed into sheet metal. Four blades are used in this model. These are clamped to the rotor base.Blades are cut in rectangular shape.

\section{Dimensions:}

Width - 170mm, Height - 620mm, Thickness - 0.5 mm

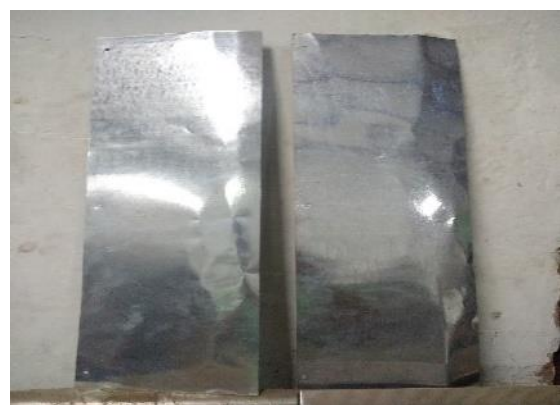

Fig. 8 Rotor Blades

\section{Fixed Base}

Base is made up of mild steel. It is circular in shape. This is the area where whole mass is supported, if this is stable and strong the entire model will be in balance. Weight of the base is bit high compared to other parts.

Dimensions:Diameter - $400 \mathrm{~mm}$, Thickness $-4 \mathrm{~mm}$

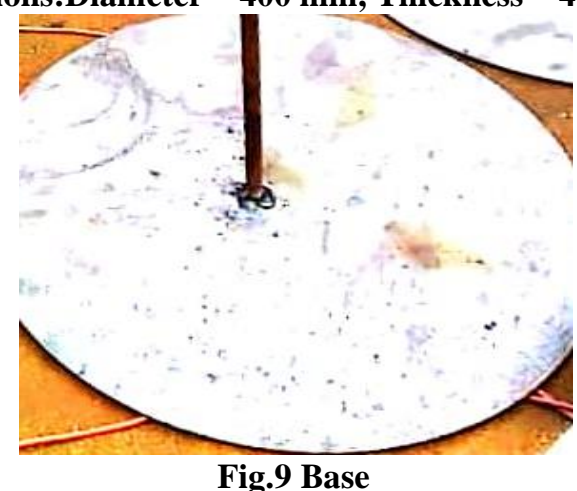

\section{Copper Coil}

An uninsulated copper wire is wound in circular shape.A 24-gauge wire is used in our project.100 number of turns and 7 coils are connected in series to generate electricity.

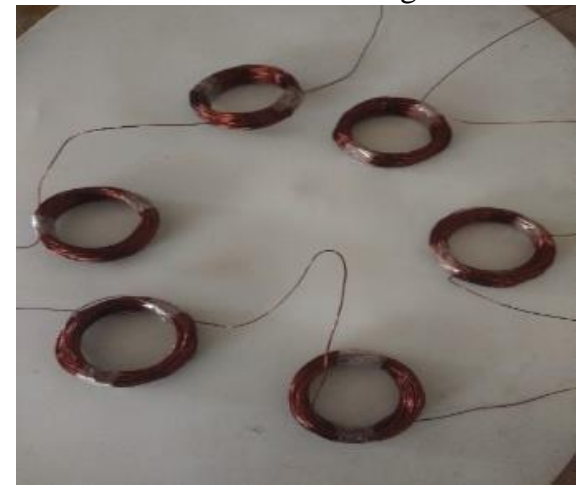

Fig.10 Copper coils

\section{RESULT AND DISCUSSION}

Field Test:

After the fabrication, the model was taken to conduct the experiments at the outdoor. The experiments are as follows,

Experiment 1

- The first experiment is to check the voltage, $\mathrm{mV}$ for different wind speed, $\mathrm{m} / \mathrm{s}$ and to tabulate those readings.

Table 1 Experiment 1

\begin{tabular}{|c|c|c|}
\hline Sl no & Wind speed, $\mathrm{m} / \mathrm{s}$ & Voltage, $\mathrm{mV}$ \\
\hline 1. & 2.778 & 5.5 \\
\hline 2. & 5.55 & 7.8 \\
\hline 3. & 8.33 & 9.2 \\
\hline 4. & 11.11 & 12.1 \\
\hline
\end{tabular}

The graph for the above readings is plotted below as shown in the below figure where the voltage is plotted in $\mathrm{Y}$-axis and Wind speed in $\mathrm{X}$-axis.

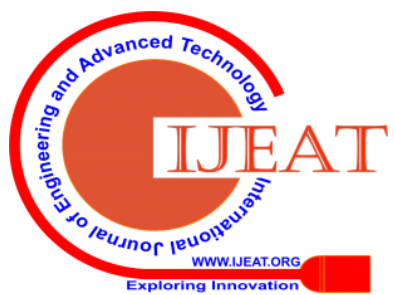




\section{Aerodynamic Analysis of Dimple effect on Airfoil}

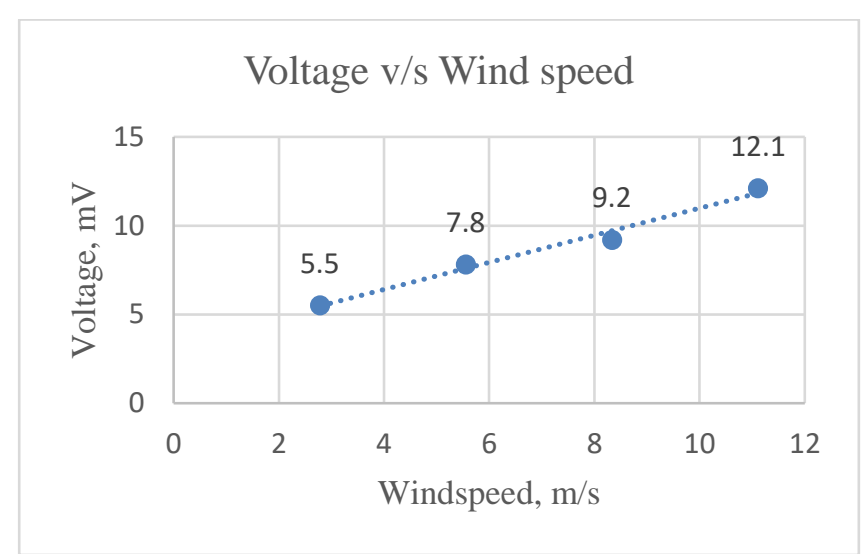

Fig.11 Graphical representation of Voltage vs Wind Speed

\section{Experiment 2}

- The second experiment is to check the value of current and to tabulate those readings as shown in the below,

Table 2 Experiment 2

\begin{tabular}{|c|c|c|}
\hline Sl no & Wind speed, $\mathrm{m} / \mathrm{s}$ & Current, $\mathrm{mA}$ \\
\hline 1. & 2.778 & 0.09 \\
\hline 2. & 5.55 & 0.12 \\
\hline 3. & 8.33 & 0.16 \\
\hline 4. & 11.11 & 0.19 \\
\hline
\end{tabular}

The graph for the above readings is plotted below as shown in the below figure where the Current is plotted in $\mathrm{Y}$-axis and Wind speed in X-axis.

\section{Current vs Wind speed}

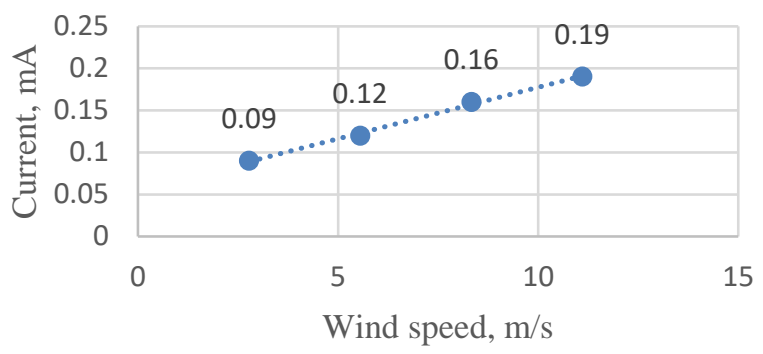

\section{Fig.12 Graphical representation of Current vs Wind} Speed

\section{Power Calculation:}

To calculate power, first we need to plot a graph of voltage vs current along $\mathrm{Y}$-axis and $\mathrm{X}$-axis respectively.

The graph for Voltage vs Current is as shown below,

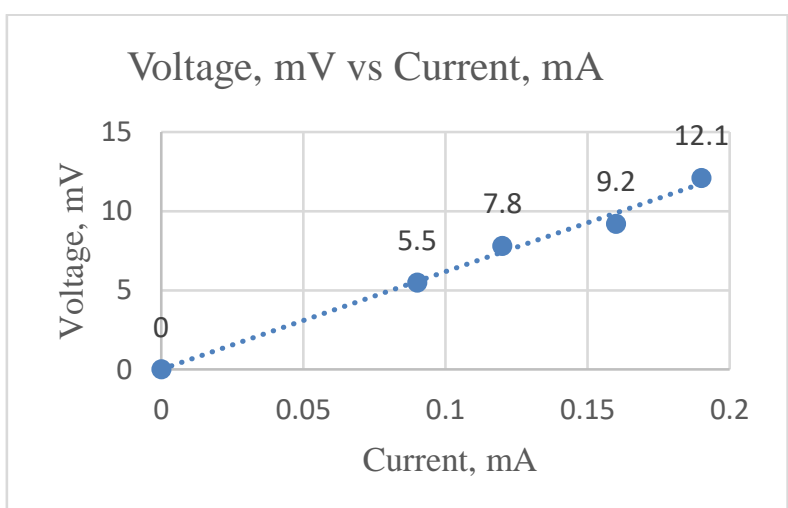

Fig. 13 Graphical representation of Voltage vs Current
We know that generally,

Power $\mathrm{P}=\mathrm{V} * \mathrm{I}$

Where,

$\mathrm{P}$ is the power, $\mathrm{V}$ is the voltage in $\mathrm{mV}, \mathrm{I}$ is the current in $\mathrm{mA}$.

From the graph, take $\mathrm{V}=5.5 \mathrm{mV}$ and $\mathrm{I}=0.09 \mathrm{~mA}$

$\mathrm{P}=5.5^{*} 10^{-3} *\left(0.09 * 10^{-3}\right)$

$\mathrm{P}=0.495 * 10^{-6}$ watts

\section{VI.CONCLUSION}

The concept of vertical axis wind turbine using magnetic levitation successfully worked. Comparing to traditional horizontal wind turbines, single maglev wind turbine having large capacity gives more output. The turbine efficiency is improved by utilization of magnets helping to spin with fast speed with negligible friction as it cancels out the stress on the shaft of the turbine. This modern design of turbine gives more power output with higher efficiency compared to conventional wind turbine. For avoiding the vibration of the rotor, shaft was used. The standard windmills having set of 1000 windmills powers 5 lakh homes while single maglev wind turbine is capable supplying power to 7.5 lakh homes. The required area for single maglev windmill is less than 100 acres while field of 1000 windmills require more than 64000 acres. From this observation we can say that a single maglev wind turbine is economical compared to conventional wind turbine.

\section{ACKNOWLEDGMENT}

This work has been supported by Head of the Department, Department of Mechanical engineering, JSSATE, Bangalore.

\section{REFERENCES}

1. Nayana Said, Maya Yeole, PriyankaPatil, P.N.Salunkhe, "Magnetic levitation is used as merit over conventional wind mill" International Journal for Scientific Research and Development(IJSRD), in 2017

2. C.M.Vivek, P.Gopalakrishan, R.Murugesh, R.Raja Mohamed, "Increasing the efficiency of wind turbine using wind energy by producing electricity" International Research journal of engineering and Technology(IRJET), in April-2017

3. Harshal Vaidya, PoojaChandadkar, Bobby Khobragade, R.K.Kharat, "The implementation of different types of wind turbine for power generation" International Journal of Research in Engineering and Technology (IJRET), in 2016

4. ParthRathod, KapilKhalik, Ketul Shah, Het Desai, Jay Shah, "The study of combined vertical axis wind turbine and optimizing combined rotor blades" International Journal of Innovation Research in Science Engineering Technology(IJIRSET), in April-2016

5. Ajay L.Parate, Pawan M Kumbhare, Rahul C Patekar, Pravingupta, "The implementation of an alternative configuration of a wind turbine for power generation" International Journal for Scientific Research and Development (IJSRD), in 2015

6. D.A.Nikam, S.M.Kherde, "Various stages of design and development of optimizing vertical wind turbine" International Journal of Engineering Research and Application (IJERA), in Nov-2015 


\section{AUTHORS PROFILE:}

Manoj L, Final year Mechanical Engineering Students, JSSATE Bangalore, Visvesvaraya Technological University.

Nithesh J, Final year Mechanical Engineering Students, JSSATE Bangalore, Visvesvaraya Technological University.

Manjunath T: Final year Mechanical Engineering Students, JSSATE Bangalore, Visvesvaraya Technological University.

Dr. GowreeshSubramanya S, Associate professor, Department of Mechanical Engineering, JSSATE Bangalore.

Profile in brief:

$\checkmark$ Doctor of Philosophy in MechanicalEngineering.

$\checkmark$ Over 12+ years of extensive industrial experience in Fluid dynamics, Thermal management, New product development, Novel technologies, Technical trouble shooting and problem solving

$\checkmark$ Philips certified Six-Sigma Green BeltEngineer.

$\checkmark$ Published around 14 internationaljournals.

$\checkmark$ Member, American Society of Mechanical Engineers(ASME) 